\title{
POLÍTICAS PÚBLICAS \\ DE ESPORTE E LAZER NO BRASIL: \\ UMA ARGUMENTAÇÃO INICIAL SOBRE A \\ IMPORTÂNCIA DA UTILIZAÇÃO DA TEORIA DOS \\ CAMPOS DE PIERRE BOURDIEU'
}

\author{
DR. FERNANDO AUGUSTO STAREPRAVO \\ Departamento de Educação Física, Universidade \\ Estadual de Maringá (Maringá - Paraná - Brasil) \\ E-mail: fernando.starepravo@hotmail.com
}

MS. JULIANO DE SOUZA

Departamento de Educação Física, Universidade

Federal do Paraná (Curitiba - Paraná - Brasil)

E-mail: julianoedf@yahoo.com.br

\author{
DR. WANDERLEY MARCHI JÚNIOR \\ Departamento de Educação Física, Universidade \\ Federal do Paraná (Curitiba - Paraná - Brasil) \\ E-mail: marchijr@ufpr.br
}

\begin{abstract}
RESUMO
No presente artigo procuramos apresentar uma possibilidade de leitura das políticas públicas de esporte e lazer no Brasil, amparados nos pressupostos teórico-metodológicos da sociologia reflexiva dos campos de Pierre Bourdieu. Mais especificamente, esse encaminhamento se dará por via da apropriação de alguns conceitos bourdieusianos como noções operatórias de análise, quais sejam: campo, habitus e capital. Deste modo, a discussão se desenvolve no sentido de demonstrar a importância de fundamentar uma agenda de pesquisas para área que contemple conjunta e relacionalmente tanto a filosofia da estrutura social quanto a filosofia das experiências primeiras dos agentes.
\end{abstract}

PALAVRAS-CHAVE: Políticas públicas; esporte e lazer; Teoria dos Campos; Pierre Bourdieu.

I. O trabalho contou com financiamento da Capes, através de bolsa discente do programa Reuni. 
mapeamento da produção científica sobre políticas públicas de esporte e lazer no Brasil é um dos objetos de pesquisa que vem sendo priorizado e sistematizado em nossa trajetória acadêmica. Na construção desse percurso, nossas primeiras constatações indicavam que a produção de conhecimento na área de políticas públicas para o esporte e lazer estava quase que exclusivamente voltada ao relato de experiências (STAREPRAVO, 2007; STAREPRAVO; MEZZADRI, 2007).

Essa exposição empírica, por sua vez, não se trata de uma condição exclusiva da área de políticas públicas de esporte e lazer. Segundo Melo (1999), a própria área de políticas públicas no Brasil se caracteriza por uma baixa capacidade de acumulação do conhecimento, fruto da proliferação horizontal de estudos de caso e da ausência de uma agenda de pesquisa. Arretche (2003), por sua vez, aponta que, enquanto os objetos de análise da área - a ação estatal, o estudo de programas governamentais bem como suas condições de emergência, mecanismos de operação e prováveis impactos - estão bem definidos, as abordagens teóricas e os métodos de investigação têm recebido uma atenção reduzida por parte dos estudiosos.

Mais recentemente, tendo como parâmetro as publicações do Grupo de Trabalho Temático de Políticas Públicas no XV Congresso Brasileiro de Ciências do Esporte realizado na cidade de Recife, em setembro de 2007, pudemos perceber um redimensionamento do panorama delineado. Como traço comum aos trabalhos apresentados, podemos dizer que: I) a maioria dos artigos é parte de trabalhos em andamento; 2) superada uma fase de relato de experiências de gestores na área, passamos a ter o predomínio de exposições empíricas, com procedimentos metodológicos bem definidos, mas que, porém, não apresentam um diálogo consistente com a literatura; 3) nos trabalhos que apresentam uma maior consistência teórica, os autores adotam uma postura de crítica ao neoliberalismo, entendendo que este modelo, em função dos interesses do capital, leva o estado a intervir cada vez menos no âmbito social, repassando esta função a setores organizados da sociedade civil (STAREPRAVO; NUNES; MARCHI JR., 2009).

Em termos de orientação teórica, essa se desenvolve no sentido de possibilitar prioritariamente o entendimento da macro-estrutura econômica e social, a fim de compreender as ações no interior dos programas analisados, bem como suas funções e objetivos. Nestes casos, a apresentação dos dados empíricos das pesquisas fica em segundo plano. A abordagem marxista nesta condição é predominante e a contingência dos processos políticos é desconsiderada (STAREPRAVO; NUNES; MARCHI JR., 2009).

Diante desse quadro ligeiramente evocado e na tentativa de ampliá-lo, procuramos apresentar neste artigo uma possibilidade de leitura das políticas públicas de 
esporte e lazer, amparados nos pressupostos teórico-metodológicos da sociologia reflexiva dos campos de Pierre Bourdieu. Mais especificamente, esse encaminhamento se dará por via da apropriação de alguns conceitos bourdieusianos como noções operatórias de análise, quais sejam: campo, habitus e capital.²

A propósito, essa filosofia, condensada em um pequeno número de conceitos fundamentais, tem como ponto central a relação de complementaridade estabelecida entre as estruturas objetivas (dos campos sociais) e as estruturas incorporadas (dos habitus) (BOURDIEU, 2007a). É exatamente essa filosofia das práticas sociais expressa nessa linha teórica que apresentaremos como proposta alternativa para balizar futuros estudos na área de políticas públicas de esporte e lazer no Brasil.

Trata-se de, a partir do estado da arte das pesquisas em políticas públicas de esporte e lazer no Brasil, apontar lacunas e fragilidades, e propor uma alternativa inicial de leitura da realidade social a partir dos pressupostos de Pierre Bourdieu. Nesse sentido, entende-se que o fenômeno social das políticas públicas de esporte e lazer, bem como seu tratamento científico por parte dos pesquisadores, estão ontologicamente imbricados, o que nos faz remeter, no decorrer do texto, à pratica dos políticos e gestores, bem como à pesquisa sobre o assunto.

\section{POLÍTICAS PÚBLICAS DE ESPORTE E LAZER E A TEORIA DOS CAMPOS DE PIERRE BOURDIEU}

Um dos principais desafios das Ciências Sociais, segundo Bourdieu, seria estudar a constituição e os mecanismos que perpetuam as formas de dominação das desigualdades sociais, bem como torná-las mais transparentes e de fácil compreensão por parte das pessoas. Daí o papel dos pesquisadores em efetivar a análise das posições relativas e das relações objetivas expressas na sociedade. Posições e relações estas que se estabelecem a partir de trocas simbólicas de manutenção e de reconhecimento das distâncias sociais, as quais, por sua vez, são determinadas pela concorrência e apropriação de bens através do acúmulo de capital econômico, social, cultural, entre outros.

Para tal empreendimento, Bourdieu inscreve seus pressupostos teóricos em um modelo de análise que envolve agentes sociais, estruturas e disposições. Em síntese,

2. Os conceitos de campo, habitus e capital, que serão detalhados no decorrer do texto, segundo os pressupostos de Bourdieu, são complementares e indissociáveis. Constituem os conceitos básicos da arquitetura teórica de Bourdieu, que pretende dar conta da dicotomia entre as estruturas objetivas (dos campos sociais) e as estruturas incorporadas (dos habitus). Nas palavras de Souza e Marchi Jr. (20 I 0, p. 300), "para desenvolver uma abordagem sobre um campo [...], Bourdieu sugere alguns passos metodológicos a serem seguidos. [...] é necessário traçar um mapa da estrutura objetiva das relações ocupadas pelos agentes ou instituições [relacionada ao acúmulo de capital], que competem pela forma legítima de autoridade específica no campo. Por fim, devem ser analisados os habitus dos agentes, isto é, os diferentes sistemas de disposições adquiridos em relação ao campo". 
seu modelo oferece categorias interpretativas da realidade, desenvolvidas em outras áreas de conhecimento e que são cabíveis para análise das questões que permeiam a discussão do esporte (MARCHI JR., 200I), assim como das políticas públicas.

Um primeiro aspecto metodológico central a ser recuperado da análise bourdieusiana, é que para se compreender devidamente o sentido e funcionamento dos mais distintos campos - a primeira noção sobre a qual iremos nos debruçar se faz necessário entender as relações entre as posições ocupadas pelos agentes e as disposições.

Em "Os usos sociais da ciência", Bourdieu (2004c) situa, a partir de uma discussão sobre as condições sociais da produção do conhecimento, de forma bastante didática, entre quais mediações teóricas se localiza a noção de campo. Para isso, apresenta duas formas de entendimento das produções culturais, para na sequência introduzir a dimensão do campo na discussão. Uma primeira forma de apreciação das obras culturais é retratada nas palavras do autor:

Grosso modo, há, de um lado, os que sustentam que, para compreender a literatura ou a filosofia, basta ler os textos. Para os defensores desse fetichismo do texto autonomizado que floresceu na França com a semiologia e que refloresce hoje em todos os lugares do mundo com o que se chama de pós-modernismo, o texto é o alfa e o ômega e nada mais há para ser conhecido, quer se trate de um texto filosófico, de um código jurídico ou de um poema, a não ser a letra do texto (BOURDIEU, 2004c, p. 19).

Em oposição, outra corrente tem como premissa que o entendimento das produções culturais está subordinado à compreensão das condições macroestruturais da sociedade, uma tradição que, enfim, "frequentemente representada por pessoas que se filiam ao marxismo, quer relacionar o texto ao contexto e propõe-se a interpretar as obras colocando-as em relação com o mundo social ou o mundo econômico" (BOURDIEU, 2004c, p. 19).

Bourdieu parece não compartilhar com nenhuma das duas vertentes, e como alternativa apresenta a noção de campo:

É para escapar a essa alternativa que elaborei a noção de campo. É uma ideia extremamente simples, cuja função negativa é bastante evidente. Digo que para compreender uma produção cultural (literatura, ciências, etc.) não basta referir-se ao conteúdo textual dessa produção, tampouco referir-se ao contexto social contentando-se em estabelecer uma relação direta entre o texto e o contexto (BOURDIEU, 2004c, p. 20).

Amparados nessas constatações de Bourdieu, podemos dizer que as análises de políticas públicas de esporte e lazer que se constituem como relatos de experiências, bem como as que privilegiam os efeitos da macroestrutura econômica e social sobre as políticas, não nos satisfazem na explicação do referido fenômeno. 
Existe um espaço intermediário, chamado de campo (nesse caso subcampo das políticas públicas de esporte e lazer), que deve ser mais bem interpretado, tanto na sua dinâmica interna, sob a lógica do Estado, como na sua relação com o restante da sociedade. Além disso, a relação direta entre texto e contexto provoca aquilo que Bourdieu (2004c, p. 20) chama de "erro do curto-circuito", isto é, um

[...] erro que consiste em relacionar uma obra musical ou um poema simbolista com as greves de Anzim, como fazem certos historiadores da arte ou da literatura. Minha hipótese consiste em supor que, entre este dois pólos, muito distanciados, entre os quais se supõe, um pouco imprudentemente, que a ligação possa se fazer, existe um universo intermediário que chamo o campo literário, artístico, jurídico ou científico, isto é, o universo no qual estão inseridos os agentes e as instituições que produzem, reproduzem ou difundem a arte, a literatura ou a ciência. Este é um mundo social como os outros, mas que obedece a leis sociais mais ou menos específicas.

Por mais que não se possam desconsiderar as condições macroestruturais da sociedade, a forma com que as mesmas refletirão em determinada questão social dependerá, em última instância, da dinâmica própria do campo em questão, que goza de certa autonomia e leis próprias de funcionamento. Nas palavras de Bourdieu (2004c, p. 20-2I):

A noção de campo está aí para designar esse espaço relativamente autônomo, esse microcosmo dotado de suas leis próprias. Se, como o macrocosmo, ele é submetido a leis sociais, essas não são as mesmas. Se jamais escapa às imposições do macrocosmo, ele dispõe, com relação a este, de uma autonomia parcial mais ou menos acentuada. E uma das questões que surgirão a propósito dos campos (ou subcampos) científicos será precisamente acerca do grau de autonomia que eles usufruem.

A questão da autonomia do campo diz respeito à capacidade de determinado espaço social ressignificar as pressões externas, de acordo com a dinâmica própria daquele espaço, ou seja, de modo a se depreender "quais são os mecanismos que o microcosmo aciona para se libertar dessas imposições externas e ter condições de reconhecer apenas suas próprias determinações internas" (BOURDIEU, 2004c, p. 2 I). Essas pressões externas sobre o subcampo das políticas públicas de esporte e lazer no Brasil, se efetivam especialmente por intermédio de questões econômicas (com as apontadas por VERONEZ, 2005), político partidárias (CAVICHIOLLI, 1996), das funções utilitaristas e assistencialistas atribuídas ao esporte e lazer (LINHALES, 200 I), ou como recurso para dissimular ou resolver mazelas sociais, como fome, desemprego e violência (MASCARENHAS, 2006).

As pressões externas, independente de sua natureza, só se exercem por intermédio do campo, são mediadas pela lógica do campo e muito dificilmente atingirão os vários espaços sociais de forma homogênea. 
As determinações externas invocadas pelos marxistas - por exemplo, o efeito das crises econômicas, das transformações, técnicas ou das revoluções políticas - só podem exercer-se pela intermediação das transformações da estrutura do campo resultantes delas. $\bigcirc$ campo exerce um efeito de refração (como um prisma): portanto, apenas conhecendo as leis específicas de seu funcionamento (seu "coeficiente de refração", isto é, seu grau de autonomia) é que se pode compreender as mudanças nas relações entre escritores, entre defensores dos diferentes gêneros (poesia, romance e teatro, por exemplo) ou entre diferentes concepções artísticas (a arte pela arte e a arte social, por exemplo), que aparecem, por exemplo, por ocasião de uma mudança de regime político ou de uma crise econômica (BOURDIEU, 2007d, p. 6I).

Essa autonomia do campo, segundo Bourdieu (2004c, p. 22), pode então ser verificada através da capacidade de refratar, re-traduzindo sob uma forma específica as pressões e demandas externas:

Dizemos que quanto mais autônomo for um campo, maior será o seu poder de refração e mais as imposições externas serão transfiguradas, a ponto, freqüentemente, de se tornarem perfeitamente irreconhecíveis. [...] Inversamente, a heteronomia de um campo manifesta-se, essencialmente, pelo fato de que os problemas exteriores, em especial os problemas políticos, aí se exprimem diretamente.

No caso das políticas públicas de esporte e lazer, tem-se a impressão que o subcampo onde se formula e se implementam as políticas é marcado por uma grande heteronomia, uma vez que as coações externas são constantes em seu funcionamento. Tal abertura, por sua vez, abre espaço para que o esporte seja usado como moeda de troca eleitoral, com um tom salvacionista (LINHALES, 200 I), ou exclusivamente sob a ótica do esporte de alto rendimento (VERONEZ, 2005).

Essa constatação, por sua vez, poderia conduzir a uma visão pessimista em relação às políticas públicas de esporte e lazer. Porém, tem-se que pensar a dimensão dos agentes na constituição do campo: "os agentes - por exemplo, as empresas no caso do campo econômico - criam o espaço, e o espaço só existe (de alguma maneira) pelos agentes e pelas relações objetivas entre os agentes que aí se encontram" (BOURDIEU, 2004c, p. 23). Ou seja, o campo não é algo estático ou estabelecido a priori, é dinâmico e está em constante transformação e movimento, principalmente pela ação dos agentes. O subcampo das políticas públicas de esporte e lazer, nesse sentido, não pode ser encarado como imutável e estático, foco de constantes críticas de autores que estudam a área. Poderá ser foco de mudanças, especialmente pela ação dos agentes. Há uma relação constante e dialética entre a pressão do campo e a ação dos agentes: 
Essa estrutura não é imutável e a topologia que descreve um estado de posições sociais permite fundar uma análise dinâmica da conservação e da transformação da estrutura da distribuição das propriedades ativas e, assim, do espaço social. É isso que acredito expressar quando descrevo o espaço social global como um campo, isto é, ao mesmo tempo, como um campo de forças, cuja necessidade se impõe aos agentes que nele se encontram envolvidos, e como um campo de lutas, no interior do qual os agentes se enfrentam, com meios e fins diferenciados conforme sua posição na estrutura do campo de forças, contribuindo assim para a conservação ou a transformação de sua estrutura (BOURDIEU, 2007c, p. 50).

A ação dos agentes e a estrutura da relação entre os mesmos estão diretamente relacionadas à posição que cada um dos agentes assume no interior do espaço social. Por conseguinte, a posição e consequente peso de cada agente (indivíduo ou instituição) no campo está relacionada ao volume de seu capital, que pode assumir várias formas. De acordo com o peso relativo do agente no campo, teremos a amplitude da pressão estrutural do campo exercida sobre ele. Quanto mais frágil o agente na composição do campo, maior será a influência estrutural do espaço sobre o mesmo; de forma contrária, quanto maior o peso do agente, mais autonomia este desfruta.

Cabe refletir qual tipo de capital é hoje mais relevante para os agentes no interior do subcampo das políticas públicas de esporte e lazer. Se, em outros momentos históricos, pensar políticas públicas de esporte e lazer era algo relegado a leigos, especialmente pela indicação de cargos a partir de critérios político-partidários, gradualmente os especialistas vêm ocupando esse espaço. Pode ser um indício de que o capital político perde um pouco o peso no interior do subcampo frente ao capital cultural específico.

As estratégias dos agentes e das instituições que estão envolvidos nas lutas [...], isto é, suas tomadas de posição [...], dependem da posição que eles ocupem na estrutura do campo, isto é, na distribuição do capital simbólico específico, institucionalizado ou não (reconhecimento interno ou notoriedade externa), e que, através da mediação das disposições constitutivas de seus habitus (relativamente autônomo em relação à posição), inclina-os seja a conservar seja a transformar a estrutura desta distribuição, logo, a perpetuar as regras do jogo ou a subvertê-las. (BOURDIEU, 2007d, p. 63-64).

Essa passagem adiciona à discussão o entendimento de que a posição dos agentes está relacionada à distribuição do capital simbólico específico daquele campo. Em outras palavras, isso indica que a concentração de capital de um tipo específico pelo agente singular é o que determinará o lugar, no contínuo entre o polo dominante e dominado, ocupado pelo mesmo. Além disso, o habitus inerente aquele campo intermediará o agir dos agentes, inclinando-o a tomadas de posição conservadoras ou transformadoras, em função da posição ocupada. Pode-se observar no interior 
do subcampo das políticas públicas de esporte e lazer, disputas constantes entre agentes estabelecidos e recém chegados, que galgam posições e tomam decisões de acordo com sua origem e posição. A constituição desses habitus, das formas de disputa legítimas, e maneiras de agir dos agentes, por sua vez, estão relacionadas à história do campo:

Mas essas estratégias, através dos alvos das lutas entre os dominantes e os pretendentes, as questões a propósito das quais eles se enfrentam, também dependem do estado da problemática legítima, isto é, do espaço de possibilidades herdado de lutas anteriores, que tende a definir o espaço de tomadas de posição possíveis e a orientar assim a busca de soluções e, em consequência, a evolução de produção. (BOURDIEU, 2007d, p. 64).

Importante ressaltar que as pessoas que constituem o campo são tratadas não apenas como um número no interior de um espectro maior, como uma classe social, por exemplo. Cada um dos gestores, políticos, esportistas, técnicos, pesquisadores são únicos e se movem em direções específicas, normalmente em situação ativa no jogo social. Bourdieu trata-as como agentes ativos na constituição e desenvolvimento do campo.

Portanto, e segundo a matriz teórica recuperada nesse artigo, é importante conduzir uma pesquisa compreendendo a lógica e as leis de funcionamento do campo, bem como considerar que os agentes ativos no processo são capazes de ressignificar e atuar de forma a legitimar ou modificar a estrutura daquele espaço social. Dito de outro modo, o que o pesquisador, impreterivelmente, deve se preocupar em recuperar mediante sua análise é as regras, bem como o papel de cada agente no "jogo".

As regras do espaço social estão estabelecidas a priori. Não obstante, os agentes por conta de suas propriedades - acúmulo de capital, experiências, posição relativa - podem agir das mais diferentes formas. Exemplo prático dessa relação entre a estrutura social e a posição ativa dos agentes pode ser observado nas Conferências Nacionais de Esporte, onde agentes, com interesses e posições distintas no subcampo, movem-se e tomam decisões sob diferentes pontos de vista, que ao final do processo, dão uma perspectiva de nova conformação do espaço social. A posição passiva dos agentes em relação às estruturas neste caso é descartada:

Onde todo mundo falava de "regras", de "modelo", de "estrutura", quase indiferentemente, colocando-se num ponto de vista objetivista, o de Deus Pai olhando os atores sociais como marionetes cujos fios seriam as estruturas, hoje todo mundo fala de estratégias matrimoniais (o que implica situar-se no ponto de vista dos agentes, sem por isso transformá-los em calculadores racionais) (BOURDIEU, 2004a, p. 21). 
Mais do que a obediência às regras, ou ações orquestradas pelo inconsciente, o agir dos agentes está diretamente relacionado ao senso de jogo, e a natureza socialmente construída, sob a qual Bourdieu constrói o conceito de habitus. Entende-se habitus como

[...] um sistema de disposições adquiridas pela aprendizagem implíita ou explicita que funciona como um sistema de esquemas geradores e gerador de estratégias que podem ser objetivamente afins dos interesses objetivos de seus autores sem terem sido expressamente concebidas para este fim (BOURDIEU, 1983, p. 94).

Habitus é algo adquirido, ligado à história individual e coletiva, bem como ao capital adquirido. A posição ativa dos agentes está diretamente ligada ao habitus adquirido:

Os "sujeitos" são, de fato, agentes que atuam e que sabem, dotados de um senso prático (título que dei ao livro no qual desenvolvo esta análise), de um sistema adquirido de preferências, de princípios de visão e divisão (o que comumente chamamos de gosto), de estruturas cognitivas duradouras (que são essencialmente produto da incorporação de estruturas objetivas) e de esquemas de ação que orientam a percepção da situação e a resposta adequada (BOURDIEU, 2007c, p. 42).

Para jogar o jogo das políticas públicas de esporte e lazer tem-se que incorporar uma série de disposições práticas, próprias do jogo, para se inserir e ser entendido como jogador. Este é um conceito central presente já nos primeiros trabalhos de Bourdieu. Foi construído para, entre outras coisas, dar conta da dicotomia entre indivíduo e sociedade. "O exemplo mais típico é a oposição, absolutamente absurda em termos científicos, entre indivíduo e sociedade, oposição que a noção de habitus enquanto social incorporado, logo, individualizado, visa superar" (BOURDIEU, 2004a, p. 45). Além disso, produz estratégias, práticas e consumos.

Sendo produto da necessidade objetiva, o habitus, necessidade tornada virtude, produz estratégias que, embora não sejam produto de uma aspiração consciente de fins explicitamente colocados a partir de um conhecimento adequado das condições objetivas, nem de uma determinação mecânica de causas, mostrando-se objetivamente ajustadas à situação (BOURDIEU, 2004a, p. 23).

O habitus é ajustado à situação justamente porque ambos são gerados socialmente, e o espaço dos possíveis é limitado pela extensão daquele espaço social. Um recém-chegado provavelmente não terá grande êxito em suas tomadas de decisão, uma vez que o habitus ainda não foi incorporado. Por mais racional que seja sua ação, ela pode gerar uma estratégia não totalmente adequada, uma vez que a ação não tem a razão como princípio. Esses novos agentes passam por um período de adaptação no interior do subcampo das políticas públicas de esporte 
e lazer, agregando formas de agir provenientes dos campos burocráticos, político, esportivo, entre outros.

É o "senso de jogo", ou habitus, que orquestra estas ações:

A ação comandada pelo "sentido de jogo" tem toda a aparência da ação racional que representaria um observador imparcial, dotado de toda informação útil e capaz de controlá-la racionalmente. E, no entanto, ela não tem a razão como princípio. (...) As condições para o cálculo racional praticamente nunca são dadas na prática: o tempo é contado, a informação é limitada, etc. E, no entanto, os agentes fazem, com muito mais frequência do que se agissem ao acaso, "a única coisa a fazer" (BOURDIEU, 2004a, p. 23).

Esta incorporação da estratégia correta, não sendo nem sempre a mais racional, é permeada pelo habitus adquirido pelos agentes. No caso do espaço onde se tomam decisões relativas às políticas públicas de esporte e lazer, o senso prático, ou habitus, parece estar bastante incorporado pelos agentes que dele fazem parte, uma vez que as decisões são tomadas dentro de uma regularidade esperada. Porém, isso não quer dizer que a incorporação do habitus conduza a tomada de decisão mais adequada do ponto de vista do Estado como espaço da primazia do público. O continuismo nas ações do poder público referente ao esporte e ao lazer, bem como a ótica do empirismo no desenvolvimento das ações, pode mostrar um lado negativo da incorporação do habitus sem a necessária reflexão sobre as ações. Isso pode ser confirmado por uma agenda de pesquisas na área que dê voz aos agentes que compõe o subcampo das políticas públicas de esporte e lazer.

O conceito se situa exatamente na posição de intermediador entre o agente, os grupos sociais e o campo, sendo portanto diferenciado e diferenciador, produto e produtor, fruto das relações e construções dos agentes. Parece-nos ser adequado focar as atenções das pesquisas em políticas públicas de esporte e lazer nesse ponto, onde se engendrar e se efetivam as ações, fruto das tomadas de decisões dos agentes.

Construir a noção de habitus como sistema de esquemas adquiridos que funciona ao nível prático como categorias de percepção e apreciação, ou como princípios de classificação e simultaneamente como princípios organizadores da ação, significava construir o agente social na sua verdade de operador prático de construção de objetos (BOURDIEU, 2004a, p. 26).

As posições dos agentes no interior do campo ou subcampo, por sua vez, estão diretamente relacionadas à posse do capital.

O espaço social é construído de tal modo que os agentes ou os grupos são aí distribuídos em função de sua posição nas distribuições estatísticas de acordo com os dois princípios de diferenciação [...] - o capital econômico e o capital cultural. (BOURDIEU, 2007b, p. 19). 
O capital - que pode existir no estado objetivado, em forma de propriedades materiais (econômico) ou, no caso do capital cultural, no estado incorporado, e que pode ser juridicamente garantido, assim como outras formas de capital, - representa um poder sobre o campo (num dado momento) e, mais precisamente, sobre o produto acumulado do trabalho passado (em particular sobre o conjunto dos instrumentos de produção) (BOURDIEU, 2004b).

As espécies de capital, a maneira dos trunfos num jogo, são os poderes que definem as probabilidades de ganho num campo determinado (a cada campo ou subcampo corresponde uma espécie de capital particular, que ocorre como poder e como coisa em jogo, neste campo), contribuindo deste modo para determinar a posição no espaço social (BOURDIEU, 2004b). Outras formas de capital (social, político, esportivo) podem ser tão ou mais importantes que o capital econômico e cultural, de acordo com o espaço social e o objeto em disputa, que se somam enquanto capital global do agente. Porém, de maneira geral,

No espaço social, os agentes são distribuídos, na primeira dimensão, de acordo com o volume global de capital (desses dois tipos diferentes) que possuam e, na segunda dimensão, de acordo com a estrutura de seu capital, isto é, de acordo com o peso relativo dos diferentes tipos de capital, econômico e cultural, no volume global de seu capital (BOURDIEU, 2007b, p. 19)

Essas considerações se aplicam aos vários espaços sociais, onde o posicionamento dos agentes e, consequentemente, suas tomadas de decisão estão relacionadas à posse global de capital, bem como à posse relativa de capital pertinente aquele campo. No caso das políticas públicas de esporte e lazer, podemos destacar que, muitas vezes, a posse de algumas variedades de capital, especialmente o capital social, político, e esportivo, por vezes se sobrepõe ao capital cultural específico na configuração do subcampo. Deste modo, é perfeitamente compreensível o fato de ex-atletas, gestores políticos e dirigentes esportivos ocuparem os cargos reservados à formulação e implementação de políticas públicas de esporte e lazer.

\section{CONSIDERAÇÕES FINAIS}

A produção científica sobre políticas públicas de esporte e lazer no Brasil atualmente se ramifica em duas perspectivas principais. De um lado da balança, temos o olhar marxista que privilegia as condições macroestruturais da sociedade e como as mesmas atingem as políticas de esporte e lazer. De outro, temos a exposição de relatos ou dados empíricos que não estabelecem um diálogo mais efetivo e consistente com as teorias.

Como alternativa a esse embate, procuramos apresentar no presente artigo a possibilidade da apropriação de alguns conceitos de Bourdieu, como noções 
operatórias e operantes de análise para estudar a área. Em síntese, percebemos que a arquitetura teórica trabalhada pelo autor nos possibilita estudar as políticas públicas de esporte e lazer contemplando tanto a filosofia da estrutura social quanto a filosofia das experiências primeiras dos agentes.

Além disso, a abordagem de Bourdieu conserva como imperativo o fato de considerar que todas as sociedades se apresentam como espaços sociais, isto é, enquanto estruturas diferenciadas e diferenciadoras que não podemos compreender verdadeiramente a não ser construindo o princípio gerador que funda estas diferenças na objetividade. (BOURDIEU, 2007c). Princípio que, inclusive, é o da estrutura da distribuição das formas de poder ou dos tipos de capital que circulam no universo social considerado - e que variam, portanto, de acordo com os lugares e os momentos.

Acresça-se em última instância a essa análise, que a posição ocupada no espaço social, isto é, na estrutura de distribuição dos diferentes tipos de capital, comanda as representações desse espaço e as tomadas de posição nas lutas para conservá-lo ou transformá-lo, ou seja, de acordo com a posição dominante ou dominada que se situam os agentes no interior do campo. (BOURDIEU, 2007b). Pensadas por essa ótica, as políticas públicas constituem-se como lócus sociais de investimento dos agentes no intuito de atrair um lucro de distinção material e simbólica às suas posições objetivas.

Dadas essas considerações abrangidas, tendemos a acreditar que a sociologia reflexiva dos campos de Pierre Bourdieu, pautada na relação de cumplicidade ontológica entre as estruturas objetivas e as estruturas incorporadas, constituiu uma interessante possibilidade teórico-metodológica para subsidiar a leitura das políticas públicas de esporte e lazer no Brasil, no sentido de avançar na apreensão e interpretação dos fênomenos sociais, bem como na amplitude e contingência dos processos políticos.

Public Policies for Sport and Leisure in Brazil: an Argument About the Importance of Initial Use of the Theory of Fields of Pierre Bourdieu

ABSTRACT: In this article we present a possibility of reading of public policy for sport and leisure in Brazil, supported in the theoretical and methodological field of reflexive sociology of Pierre Bourdieu. More specifically, the referrals will be made by way of appropriation of some concepts and notions Bourdieusian operative analysis, which are: field, habitus and capital. Thus, the discussion is developed in order to demonstrate the importance of basing a research agenda for the joint area that includes both relationally and the philosophy of social structure and the philosophy of the experiences first of the agents. KEYWORDS: Public policy; sport and leisure; Theory of Fields, Pierre Bourdieu. 
Políticas públicas para deporte y ocio en Brasil: un argumento inicial sobre la importancia del uso de la Teoría de Campos de Pierre Bourdieu

RESUMEN: En este artículo se presenta una posibilidad de lectura de las políticas públicas para el deporte y el ocio en Brasil, con el apoyo en el campo teórico y metodológico de la sociología reflexiva de Pierre Bourdieu. Más concretamente, las referencias se harán através de la apropriación de algunos conceptos y nociones operativas de análisis de Bourdieu, que son: campo, habitus y capital. Así, la discusión se desarrolla con el fin de demostrar la importancia de basar un programa de investigación para el área común, que incluye tanto relacional y la filosofía de la estructura social y la filosofia de las primeras experiencias de los agentes. PALABRAS CLAVE: Políticas Públicas; deporte y el ocio; Teoría de Campos, Pierre Bourdieu

\section{REFERÊNCIAS}

ARRETCHE, M. T. S. Dossiê agenda de pesquisas em políticas públicas. Revista Brasileira de Ciências Sociais, São Paulo, v. I8, n. 5I, p. 7-10, fev. 2003.

BOURDIEU, P. Coisas ditas. São Paulo: Brasiliense, 1983.

BOURDIEU, P. Fieldwork in philosophy. In: BOURDIEU, P. Coisas ditas. São Paulo: Brasiliense, 2004a.

BOURDIEU, P. O poder simbólico. 7. ed. R io de Janeiro: Bertrand Brasil, 2004b.

BOURDIEU, P. Os usos sociais da ciência: por uma sociologia clínica do campo cientííco. São Paulo: Ed. da Unesp, 2004c.

BOURDIEU, P. Razões práticas: sobre a teoria da ação. Campinas: Papirus, 2007a.

BOURDIEU, P. Espaço social e espaço simbólico. In: BOURDIEU, P. Razões práticas: sobre a teoria da ação. Campinas: Papirus, 2007b.

BOURDIEU, P. O novo capital. In: BOURDIEU, P. Razões práticas: sobre a teoria da ação. Campinas: Papirus, 2007c.

BOURDIEU, P. Por uma ciência das obras. In: BOURDIEU, P. Razões práticas: sobre a teoria da ação. Campinas: Papirus, 2007d.

CAVICHIOLLI, F. R. Políticas públicas para o esporte e lazer: tentativa de mudanças. 1996. Dissertação (Mestrado em Educação) - Universidade Metodista de Piracicaba, Piracicaba, 1996.

MARCHI JR., W. "Sacando" o voleibol: do amadorismo à espetacularização da modalidade no Brasil (1970-2000). 200 I. Tese (Doutorado em Educação Física) - Faculdade de Educação Física, Universidade Estadual de Campinas, Campinas, 2001.

LINHALES, M. A. Jogos da política, jogos do esporte: subsídios à reflexão sobre políticas públicas para o setor esportivo. In: MARCELINO, N. C. (Org.). Lazer e esporte: políticas públicas. 2. ed. Campinas: Autores Associados, 2001. 
MASCARENHAS, F. Exclusão social clube: problema para as políticas públicas e gestão em esporte e lazer. Lecturas Educación Fisica y Deportes, Buenos Aires, v. 95, p. I - I5, 2006.

MELO, M. A. Estado, governo e políticas públicas. In: MICELI, S. (Org.). O que ler na ciência social brasileira (1970-1995). São Paulo: Anpocs, 1999. p. 59- 100.

STAREPRAVO, F. A. Políticas públicas para o esporte e lazer: conselhos municipais de esporte e lazer e outras formas de participação direta. In: CONGRESSO BRASILEIRO DE CIÊNCIAS DO ESPORTE, I5., 2007, Recife. Anais ... Recife: CBCE, 2007.

STAREPRAVO, F. A.; MEZZADRI, F. M. Algumas contribuições de Pierre Bourdieu e Norbert Elias à discussão de políticas públicas para o esporte e lazer. In: X SIMPÓSIO INTERNACIONAL PROCESSO CIVILIZADOR, I0., 2007, Campinas. Anais... Campinas: FEF-UNICAMP, 2007.

STAREPRAVO, F. A.; NUNES, R. J. S.; MARCHI JR., W. Agenda de pesquisa em políticas públicas de esporte e lazer: uma leitura a partir do GTT de Políticas Públicas no XV Congresso Brasileiro de Ciências do Esporte. In: CONGRESSO BRASILEIRO DE CIÊNCIAS DO ESPORTE, 16., 2009, Salvador. Anais... Salvador: CBCE, 2009.

SOUZA, J. de; MARCHI JR, W. Por uma sociologia reflexiva do esporte: considerações teórico-metodológicas a partir da obra de Pierre Bourdieu. Movimento, Porto Alegre, v. I6, n. I, p. 293-315, 2010.

VERONEZ, L. F. Quando o Estado joga a favor do privado: as políticas de esporte após a Constituição Federal de 1988. Tese (Doutorado em Educação Física) - Faculdade de Educação Física, Universidade Estadual de Campinas, Campinas, 2005.

Recebido em: 27 abr. 2010

Aprovado em: 24 ago. 2010

Endereço para correspondência:

Fernando Augusto Starepravo Departamento de Educação Fisica Avenida Colombo, 5.790

Campus Universitário CEP 87.020-900

Maringá-PR 